\title{
EXPERIMENTAL RESEARCH OF INFLUENCE OF A RELATIVE PARTICLES POSITIONING IN A GAS STREAM ON CHARACTERISTICS OF THEIR AERODYNAMIC TRACES
}

\author{
Roman S. Volkov ${ }^{1, *}$, Maria M. Osmolovskaya ${ }^{1}$, and Irina P. Ozerova ${ }^{1}$ \\ ${ }^{1}$ National Research Tomsk Polytechnic University, 634050 Tomsk, Russia
}

\begin{abstract}
The cycle of experimental studies on determination of length of aerodynamic traces of the particles which are flowed round by an air stream is executed. When carrying out researches, panoramic optical methods for diagnostics of multiphase flows of PIV and PTV were used. Velocities of an air flow were varied in the range of 1-3 m/s. The sizes of particles changed from $1 \mathrm{~mm}$ to $5 \mathrm{~mm}$. The defining influence of the sizes of particles and velocities of an air stream on length of aerodynamic traces is established. Influence of a relative positioning of particles on features of formation of an aerodynamic trace is shown.
\end{abstract}

\section{Introduction}

Nowadays huge number of technologies use single-phase and multiphase drop streams [13].The most widespread and at the same time complex challenge is the choice of initial parameters of such streams. It is especially difficult to predict such parameters when drops (or particles) move through a counter gas flow. In that case the drops in a stream going the first exert considerable impact on the subsequent drops. Such influence is shown, first of all, due to decrease in speeds of an air stream in a trace of a drop (particle).

For correct prediction of the initial parameters of a stream (speeds and the sizes of drops) it is necessary to know the features of aerodynamic traces of drops. Besides it is important to understand how the relative positioning of drops influences the characteristics of aerodynamic traces. Such researches can be carried out by using modern diagnostic PIV systems [2-5].

The purpose of this work - experimental research of influence of a relative particles positioning in a gas stream on characteristics of their aerodynamic traces.

\section{Experimental methods and the experimental setup}

For carrying out researches the experimental setup which was designed for these purposes was used. The scheme of the experimental setup is given in fig. 1. Experimental setup

* Corresponding author: romanvolkov@tpu.ru 
contained in the basis a complex for diagnostics of parameters of multiphase streams. The stand (fig. 1) consisted of the following registration equipment: high-speed CCD video camera of type "IMPERX IGV B2020M" (image format is $2048 \times 2048$ pixels, frame rate is not less than $1.5 \mathrm{~Hz}$, delay between two consecutive shots is no more than $5 \mu \mathrm{s}$ ); a solid double-pulse Nd:YAG laser of type Quantel "EverGreen 70" (wavelength is $532 \mathrm{~nm}$, pulse energy is no more than $74 \mathrm{~mJ}$, pulse duration is not more than $12 \mathrm{~ns}$, repetition rate is less than $15 \mathrm{~Hz}$ ); a synchronizing processor (sampling signals is no more than $10 \mathrm{~ns}$, supports the modes of external and internal start-up).



Fig. 1. Scheme of the experimental setup: 1 - work station; 2 - circulation loop; 3 - air fan; 4 - glass contour; 5 - spherical particle; 6 - CCD camera; 7 - double pulsed Nd:YAG laser; 8 - laser optics; 9 - laser sheet; 10 - power supply of Nd:YAG laser; 11 - synchronizer of signals; 12 - openings for installation in a contour of spherical particles and tracers; 13 - supporting structure of circulation loop; 14 - speed controller of air fan.

As registration area the glass part (4) of a circulating loop (3) was used. For these purposes opposite to glass part at an angle of 90 degrees, CCD camera (6) and the double pulsed Nd:YAG laser (7) were set. The researched spherical particle (5) was fixed in registration area of a CCD camera (6) in the glass channel (4) on its axis of symmetry.

As material of particles plasticine has been chosen. All particles were made spherical shape. The sizes (diameters $-d_{0}$ ) of particles changed from $1 \mathrm{~mm}$ to $5 \mathrm{~mm}$. In each experiment at the same time from 1 to 2 particles were used. For creation of an air stream in a circulating loop (2) the air fan (3) complete with the speed controller (14) has been used. Air speed $\left(U_{\mathrm{g}}\right)$ in the registration area changed in the range of $1-3 \mathrm{~m} / \mathrm{s}$. For each value of a particle diameter $\left(d_{0}\right)$ and air velocity $\left(U_{\mathrm{g}}\right)$ not less than 10 experiments were made. Length of an aerodynamic trace $\left(l_{\text {trace }}\right)$ of a particle, and also characteristics and features of air flow were defined in each experiment

For determination of an air stream velocities PIV [4] and PTV [5] methods have been used. PIV and PTV techniques are based on the photographing of flow images appeared in the plane intersected by laser light, given that the optical axis of the CCD camera is perpendicular to the plane of laser light. We introduced the tracers in the air flow. To do it, we used the specific device that is a metallic container. Air compressor was connected to this container. Using the metal hose, the compressed (about $200 \mathrm{kPa}$ ) mixture of $\mathrm{TiO}_{2}$ (particle size is less than $1 \mu \mathrm{m}$, the maximum use temperature $-2300 \mathrm{~K}$ ) and air was injected into loop (2) through an openings (12). After injecting, the tracers continued to move through the air flow produced by air fan (3) inside of the loop (2).

The error in determining of $U_{\mathrm{g}}$ using this approach did not exceed $2 \%[2,3]$. 


\section{Results and discussion}

As a result of carrying out experimental studies the two-dimensional velocity fields illustrating process of a spherical particle streamlining by air stream were received. During the analysis of videograms of process lengths of aerodynamic traces have been determined. After comparison of the received results dependences of the $l_{\text {trace }}$ parameter on velocities of an air stream $\left(U_{\mathrm{g}}\right)$ and initial diameter of the used particles $\left(d_{0}\right)$ have been constructed. The received results are presented at fig. 2 .
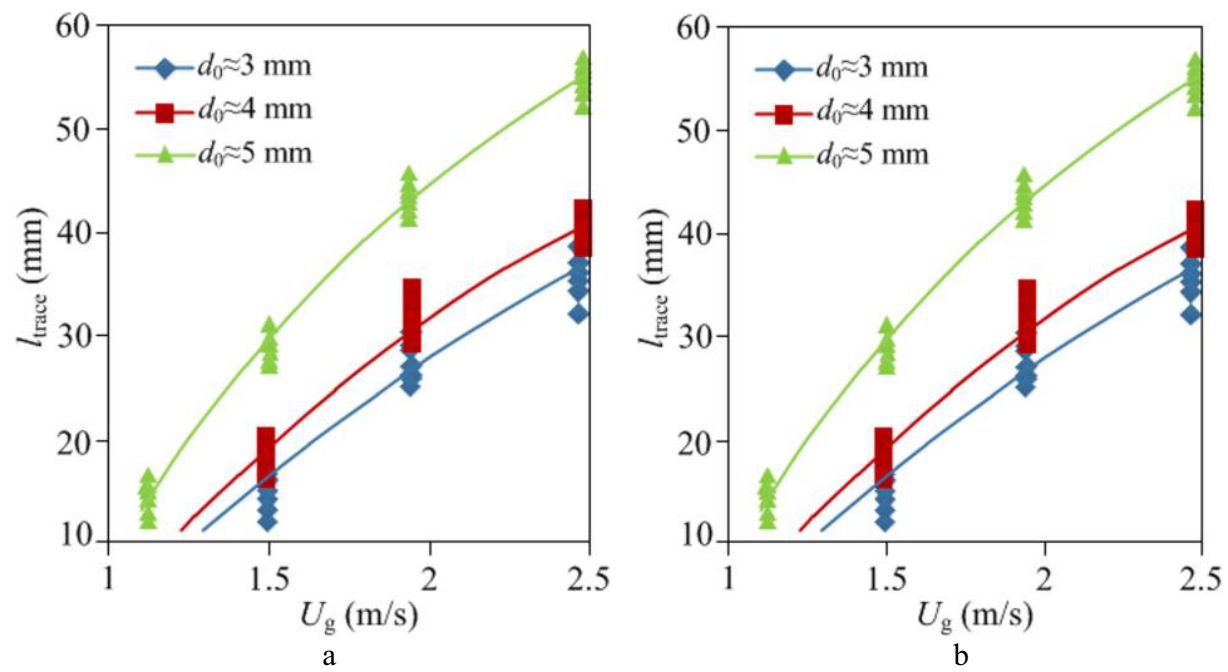

Fig. 2. Dependences of length of an aerodynamic trace of a particle on velosities of air flow (a) and sizes of a particle (b).

The analysis of fig. 2 allows to speak about the defining influence of speed of $U_{\mathrm{g}}$ on length of an aerodynamic trace (fig. 2a). So, growth of $U_{\mathrm{g}}$ by 2.5 times leads to increase in $l_{\text {trace }}$ values more than by $3-5$ times. And for rather large particles $\left(d_{0} \approx 5 \mathrm{~mm}\right)$ influence more essential. Influence of initial diameter of a particle $\left(d_{0}\right)$ on $l_{\text {trace }}$ values has more moderate character (fig. 2b). Increase of $d_{0}$ in the range of 3-5.5 mm leads to increase of the $l_{\text {trace }}$ parameter no more than by $1.5-2$ times.

Such result (fig. 2) shows importance of accounting of such parameter as $U_{\mathrm{g}}$ when forecasting features of a streamlining of spherical particles. It is important to consider especially this feature in technologies which use the drop flows moving in opposite directed gas stream. For example, vaporizing cooling of water in coolers of ventilator type, thermal (fire) treatment of liquids and water fire extinguishing. Selecting the necessary parameters of a drop stream it is possible to provide conditions under which drops will pass almost freely a counter gas flow. Or opposite, it is possible to reach conditions of full braking of a stream.

Experimental researches of influence of a relative droplets positioning in a gas stream on characteristic of their aerodynamic traces have been conducted. The example of the obtained data illustrating features of a streamlining of two spherical particles $\left(d_{0} \approx 5 \mathrm{~mm}\right)$ is given at fig. 3 . 



Fig. 3. 2D velocity fields of an air stream obtained with use of the PIV method.

During experiments it has been established that at rapprochement of particles on distance less than $1 \cdot d_{0}$ is observed one general aerodynamic trace. At the same time length of the integrated trace for $5-10 \%$ exceeds length of an aerodynamic trace of a single particle. During removal of particles on distance more $(1.5-2) \cdot d_{0}$ at each particle is observed the separate aerodynamic trace.

\section{Conclusion}

During experimental studies features of a streamlining by an air stream of spherical particles are established. The influence of velocity of an air stream on the length of an aerodynamic trace of a particle was shown. It is established that the size of a particle renders moderate value on the length of an aerodynamic trace. It is recorded that at rapprochement of two particles on distance less than $1 \cdot d_{0}$ the integrated aerodynamic trace which length for $5-10 \%$ exceeds length of a trace of a single particle arises.

\section{Acknowledgments}

The investigation was supported by Russian Science Foundation (project 14-39-00003).

\section{References}

1. A.Yu. Varaksin, High Temp. 51, 3 (2013)

2. R.S. Volkov, G.V. Kuznetsov, P.A. Strizhak, Int. J. Heat Mass Transfer 79 (2014)

3. P.A. Strizhak, R.S. Volkov, Exp. Therm. Fluid Sci. 75 (2016)

4. J.V. Simo Tala, S. Russeil, D. Bougeard, J.-L. Harion, Exp. Therm. Fluid Sci. 50 (2013)

5. D. Damiani, E. Meillot, D. Tarlet, J. Therm. Spray Technol. 23, 3 (2014) 